\title{
As fontes judiciais como material de pesquisa para a História Social e Política: os processos de acidentes de trabalho no contexto da legislação social
}

The judicial sources as research material for the Social and Political

History: the processes of work accidents in the context of social legislation

\author{
Bruno Mandelli* \\ João Henrique Zanelatto**
}

Palavras-chave:

História social e política

Fontes judiciais

Leis de acidentes de trabalho

Keywords:

Social and political History

Judicial sources

Occupational accident laws
Resumo: Este artigo aborda a importância das fontes judiciais para as pesquisas no campo da História social e política, em especial às questões relativas ao mundo do trabalho. Desde as instituições jurídicas e seus modos de funcionamento, passando pela história do cotidiano dos trabalhadores e das suas lutas por direitos, bem como das variadas concepções em torno das leis, dos direitos e da justiça, as fontes jurídicas fornecem um rico material para análise do historiador. Especificamente, o artigo problematiza a questão da pesquisa nos arquivos judiciais, em especial dos processos de acidentes de trabalho, como uma fonte jurídica que possui especificidades que devem ser levadas em consideração pelo pesquisador. Para tanto, aprofunda uma análise da legislação de acidentes de trabalho no Brasil desde a sua instituição, em 1919, até a Reforma da Lei de Acidentes de Trabalho, em 1944, e a sua relação com a instituição da Justiça do Trabalho, outra importante produtora de fontes jurídicas para as pesquisas relacionadas ao mundo do trabalho.

Abstract: This article discusses the importance of judicial sources for research in the field of social and political history, especially issues related to the world of work. From the juridical institutions and their modes of operation, to the history of worker's daily life and their struggles for rights, as well as the varied conceptions surrounding laws, rights and justice, legal sources provide a rich material for analysis of the historian. Specifically, the article problematizes the question of the search in judicial archives, especially of the processes of work accidents, as a legal source that has specifics that must be taken into account by the researcher. In order to do so, it analyzes an analysis of labor accident legislation in Brazil from its institution in 1919 until the Reform of the Labor Accident Law in 1944 and its relationship with the Labor Justice institution, another important producer of legal sources for research related to the world of work.

Recebido em 03 de dezembro de 2018. Aprovado em 18 de fevereiro de 2019.

\section{Introdução: entrelaçando a história social e política nas pesquisas com fontes judiciais}

Nota-se que nas últimas décadas as fontes judiciais têm ganhado relevância nas pesquisas e nas análises das Ciências Humanas, especialmente na História. Na história social e política, por exemplo, vem se multiplicando o desenvolvimento de pesquisas que envolvem o campo jurídico.

No que se refere à história política, essa abordagem enfrentou uma série de críticas, como o "[...] descrédito em que foi lançado durante algum tempo o estudo dos fatos políticos pela afirmação de um interesse por outras dimensões

\footnotetext{
* Doutorando do Programa de Pós-Graduação em História da Universidade Federal do Rio Grande do Sul (UFRGS). E-mail: <bruno.o.mandelli@ gmail.com>.

** Professor de História da Universidade do Extremo Sul Catarinense (UNESC). Pós-doutor em História pela Universidade Federal do Paraná (UFPR). E-mail: <jhz@unesc.net>.
} 
da história" (RÉMOND, 2003, p. 44), que foi, durante um bom tempo, símbolo de uma história fora de moda; afinal, era "[...] admitida para ser essencialmente relacionada ao Estado; em outras palavras, era mais nacional e internacional, do que regional" (BURKE, 1992, p. 10). Esse descrédito emergiu a partir das críticas contundentes que recebeu do grupo dos Annales, provocando uma marginalização da dimensão política dos fatos sociais, pois a consideravam literária, passível de ser romanceada e, sobretudo, por fundamentar-se em conflitos localizados e de curta duração. "Cada vez mais essa história será conhecida como tradicional” (FALCON, 1997, p. 68).

Na década de 1960, a Tradição Marxista e o Estruturalismo não poupariam críticas à história política, contribuindo também para o seu descrédito, pois a consideravam um tipo de história que estava ancorada exclusivamente no acontecimento, na linearidade e na narração dos fatos. Portanto, historiadores das três correntes - Annales, Marxismo e Estruturalismo - foram responsáveis pelo descrédito sofrido pela história política até o final da década de $1960^{1}$.

O processo de revalorização e de renovação da história política ocorreu ao longo da década de 1970. Jacques Julliard foi um dos primeiros historiadores a propor a reversão do quadro da história política tradicional. Inicialmente, apontou seus vícios e defeitos ${ }^{2}$. Em seguida, depois de expor os defeitos e vícios, Julliard propôs a necessidade de renovação da história política e foi enfático ao considerar que "[...] marxista ou não, o historiador não pode desinteressar-se do problema da natureza social do poder político" (JULLIARD, 1988, p. 181). Assim, até a década de 1970, a história política era "a própria imagem e o exemplo perfeito da história dita factual" (RÉMOND, 2003, p. 16-17). Ela privilegiava o particular e o nacional, dando as costas para a possibilidade de comparações no espaço e no tempo.

A renovação que a história política vem experimentando nas últimas décadas pode ser entendida levando-se em consideração a amplitude das transformações sociais e as "novas orientações da pesquisa histórica” (RÉMOND, 2003, p. 21). Assim, na década de 1980, a situação de descrédito foi sendo modificada, a renovação da história política tomava fôlego " $[. .$.$] com o gradativo abandono da história$ política tradicional em favor de uma compreensão do político na história (FÉLIX, 1999, p. 58).

Outra dimensão ocorrida na esteira dessa renovação estava ligada à noção de paixão usada por Pierre Ansart (1997) ao trabalhar com a afetividade - do amor e do ódio, das emoções e dos sentimentos - que acompanha a vida política. Assim como dos momentos de angústia e revolta ou de simpatia e afeição. Na década de 1990, Jean-François Sirinelli percebeu, na emergência da nova história cultural, o ressurgimento da história política. A aproximação da cultura com a história política possibilitou a incorporação por esta última de novos objetos e recortes. Para Sirinelli (1998), a política vista a partir do universo cultural contribuiu para um maior entendimento da complexidade das relações sociais.

Nessa direção, destacamos o conceito de cultura política, entendido como um "[...] conjunto de valores, práticas e representações políticas, partilhado por determinado grupo humano, que expressa uma identidade coletiva e fornece leituras comuns do passado, assim como fornece inspiração para projetos políticos direcionados ao futuro" (MOTTA, 2009, p. 21). A cultura política pode mobilizar sentimentos (paixões, esperanças e medos), valores (moral, honra, solidariedade) e fidelidade às tradições (família, nação, líderes). Seu conceito permite uma compreensão rica e sofisticada do comportamento político. Esse processo de renovação e valorização da história política refletiu-se também em trabalhos de âmbito regional e local. Já a aproximação da cultura com a história política e com o conceito de cultura política possibilitou entrelaçar pesquisas sobre a história política e a história social do trabalho.

Em relação à história social, os historiadores têm feito uso da pesquisa nos documentos judiciais nos últimos anos, com uma ampla gama de temas e de problemáticas de pesquisa: desde as instituições jurídicas e seus modos de funcionamento, passando pela história do cotidiano dos trabalhadores e das suas lutas por direitos, bem como das variadas concepções em torno das leis, dos direitos e da justiça (GOMES; SILVA, 2012, p. 26). 
Todas essas representações abarcam sujeitos dos mais variados matizes sociais que entram nas fontes judiciais de formas distintas: escravos, indígenas, os chamados "trabalhadores livres", homens e mulheres anônimos que entram em cena diante de algum conflito, ou exigindo a aplicação de determinada norma ou costume para defesa de um direito (GOMES; SILVA, 2012, p. 26).

A busca por direitos - seja por meio de sindicatos, greves e mobilizações operárias, seja de tribunais - passou a fazer parte da vida dos trabalhadores brasileiros a partir da década de 1930 e 1940.

É importante salientar que, como ainda não existia a Justiça do Trabalho (oficializada em maio de 1941), a competência do julgamento das questões de acidentes laborais ficava a cargo da Justiça Comum. Contudo, mesmo com essa permanência do monopólio da Justiça Comum sobre a referida legislação, é importante ressaltar que o advento da primeira Lei de Acidentes consolidou um marco jurídico importante no país, pois deslocou do Código Civil para o incipiente Direito do Trabalho a avaliação e o julgamento de algumas questões relativas ao mundo do trabalho (a questão acidentária nesse caso). Nesse sentido, Samuel Fernando de Souza afirma a importância da primeira Lei de Acidentes como um marco na formação do Direito do Trabalho no Brasil:

A publicação da Lei de Acidentes de Trabalho foi um passo importante para o processo de regulamentação das relações de trabalho no Brasil. Ela teria definido o direito do trabalho como ramo separado do Código Civil brasileiro, passando-se a considerar o acidente decorrência de riscos próprios do ambiente de trabalho industrial, assegurando ao operário o direito à reparação. (SOUZA, 2006, p. 32).

Dessa maneira, é provável que, se não fosse a entrada em cena de um processo judicial, quer seja de um crime, ou, talvez, em um processo de acidente de trabalho (que será o foco do presente estudo) - em que o trabalhador entra contra seu patrão na defesa de um direito -, esses milhares de trabalhadores e trabalhadoras ficassem no anonimato da história (MANDELLI, 2018, p. 52).

Como exemplo da importância do estudo dessas fontes, Chalhoub (2005) afirma que, até o século XIX, praticamente todos os crimes de homicídio aconteciam entre as relações de pessoas que se conheciam ou de parentesco muito próximo: vizinhos, brigas entre senhores e escravos, que resultavam em mortes em ambos os lados, não raramente ocorriam no interior de comunidades pequenas, o que informavam "um momento de crise profunda em uma comunidade" (CHALHOUB, 2005, p. 5).

O conflito latente nos arquivos, portanto, emerge durante a pesquisa do historiador, que se vê, muitas vezes, diante de dilemas do passado não resolvidos. É por esse caminho que a pesquisa nos arquivos judiciais emerge com o objetivo dos pesquisadores iluminarem as experiências dos trabalhadores e trabalhadoras em aspectos que não haviam sido abordados, como destaca Chalhoub (2005, p. 5): “[...] o cotidiano nas fábricas, as relações de sociabilidade no botequim, as relações de amor dos trabalhadores e etc.".

Sobre a pesquisa nos arquivos judiciais, deve-se ressaltar, tal como sugeriu Farge (2009, p. 10) que "o arquivo judicial é específico". Distintamente de outras fontes, como os impressos, que foram escritos para serem dirigidos a um grande público, os documentos judiciais não eram destinados ao conhecimento de todos. Como um vestígio de vidas que não queriam, em um primeiro momento, que suas situações particulares fossem expostas a um amplo número de pessoas, ele emerge como um fragmento particular. Realidades de violências ou de repressão, situações de defesa de uma ideia pessoal ou coletiva, que levaram aquelas pessoas a exporem pensamentos e falas que, talvez, em outra situação particular de suas vidas, não teriam exposto. Farge (2009, p. 35), mais uma vez, contribui com sua análise dos arquivos:

Por trás das palavras expostas nos autos, pode-se ler a maneira como cada um procura se posicionar diante de um poder coercitivo, como cada um 
articula sua própria vida, com êxito ou não, em confronto com a do grupo social e em relação às autoridades.

No âmago desse debate, é fundamental refletir que o arquivo judicial não surgiu como uma fonte documental direta a ser pesquisada por um historiador na posteridade. $\mathrm{O}$ arquivo não possuía esse caráter quando foi criado: “[...] a testemunha, o vizinho, o ladrão, o traidor e o rebelde não queriam registro; outras necessidades fizeram com que suas palavras, seus atos e seus pensamentos fossem consignados" (FARGE, 2009, p. 16). Isso reforça a importância de o historiador questioná-lo: saber de sua história, como foram produzidos, em quais circunstâncias, em qual contexto, de que maneira, por que ficaram tanto tempo no esquecimento.

Todavia, se os processos judiciais são dotados de singularidades. O são, ainda mais, os processos de acidentes de trabalho, que são regidos pela legislação acidentária. Portanto, para aprofundar nessa temática, após essa breve reflexão sobre a natureza dos arquivos judiciais enquanto fonte, será agora problematizado o lugar social em que a lei se materializava, isto é, a instituição judiciária; no caso da aplicação das leis de acidente de trabalho, a Justiça Comum. Tal como afirmou Grinberg (2009, p. 121): "Para trabalhar com qualquer documentação, é preciso saber ao certo do que ela trata, qual é a sua lógica de constituição, bem como as regras que lhe são próprias".

\section{O lugar social: a legislação de acidentes de trabalho}

Nas primeiras décadas do século XX, centradas principalmente no eixo Rio-São Paulo, as mobilizações e greves operárias passaram a impulsionar e pressionar os parlamentares para que fossem criados direitos que beneficiassem os trabalhadores e lhes garantissem alguma proteção social. Estes possuíam como pauta de reivindicações uma lista que abarcava, entre outras, a jornada de oito horas, aposentadoria, a regulamentação do trabalho da mulher, o direito a férias, bem como seguro contra acidentes (FERRAZ, 2010). Isso porque as condições de trabalho, em geral, eram muito precárias em todo País no começo do século $\mathrm{XX}$, com jornadas quase sempre superiores a dez horas. Além do trabalho de menores em várias funções perigosas, "[...] somavam-se à insalubridade do ambiente para formar um quadro de mortes e acidentes constantes" (MATTOS, 2009, p. 42).

Um projeto de lei sobre acidentes de trabalho, que fora apresentado pelo senador paulista Adolfo Gordo, em 1915, “[...] foi particularmente bem recebido pelo Centro Industrial Brasileiro [...] declarando-se este prontamente favorável à adoção de regulamentação específica sobre um dos mais espinhosos problemas sociais da indústria moderna" (FERRAZ, 2010, p. 207).

Porém, mesmo com o interesse de setores empresariais na apresentação de um projeto que pudesse lhes garantir um controle sobre as situações imprevisíveis no âmbito laboral, como de acidentes e de doenças profissionais, não fossem as pressões internas - do movimento operário em suas pautas pela redução da jornada de trabalho e melhoria das condições de trabalho, seguro contra acidentes e as externas - com o fim da Primeira Guerra em 1919 e o Tratado de Versalhes no qual o Brasil foi signatário que efetivou a criação da Organização Internacional do Trabalho (OIT), entre outras medidas, recomendava o reconhecimento dos novos direitos sociais, como a já mencionada redução da jornada de trabalho para oito horas diárias e no máximo de 48 horas semanais.

Em virtude dessa conjuntura mundial e nacional, surgiu a primeira legislação que regulamentou os acidentes de trabalho no Brasil. Foi criado, no ano de 1919, por meio do Decreto $\mathrm{n}^{\circ} 3.724$, de 15 de janeiro de 1919 , regulamentado posteriormente pelo Decreto $\mathrm{n}^{\circ} 13.498$, de 12 de março de 1919, constituindo-se, portanto, na primeira lei brasileira que adotou a "teoria do risco profissional", a qual teve como criador Félix Faure, em 1883 (ARAVANIS, 2009, p. 31). Essa jurisprudência, conhecida também pela teoria do "fato do trabalho", implicava a responsabilização de o empregador pagar uma indenização ao operário "[...] quando o acidente ocorresse pelo fato do trabalho ou durante este". 
O acidente era visto como uma espécie de fato natural e próprio da atividade laborativa." (FERRAZ, 2010, p. 215). Todavia, a definição de acidente de trabalho era bastante restrita, pois incluía tão somente as "moléstias" adquiridas pelo exercício do trabalho, o que desconsiderava as doenças causadas por suas condições degradantes.

Desse modo, estavam fora de proteção os casos de acidentes em que fossem constatados casos de força maior ou dolo da própria vítima, o que proporcionava brechas para que o empresariado pudesse contestar o pagamento das indenizações.

Segundo Anna Beatriz de Sá Almeida (2015), essa lei foi criticada na época por juristas e especialistas que a denunciavam pelo fato de não conter dispositivos relacionados à questão preventiva dos acidentes de trabalho. Como exemplo, cita o médico Afrânio Peixoto, que, em estudo publicado em 1926, faz uma análise da lei de 1919 e uma crítica de esta tratar exclusivamente das "[...] moléstias exclusivas do exercício do trabalho" (ALMEIDA, 2015, p. 75). Além desse fator primordial que regia toda a legislação de acidentes, o art. 19 da lei determinava que: "Todo o acidente de trabalho que obrigue o operário a suspender o serviço ou se ausentar, deverá ser imediatamente comunicado à autoridade policial do logar, [sic] pelo patrão, pelo próprio operário, ou qualquer outro" (BRASIL, 1919).

Nesse aspecto, a Lei de Acidentes se assemelha aos procedimentos da Justiça do Trabalho, uma vez que nesta "as reclamatórias trabalhistas são, em geral, instauradas por uma das partes (patrões ou empregados)" (SPERANZA; SCHMIDT, 2012, p. 222). Desse modo, a semelhança se deve ao fato de que os processos de acidentes podem ser comunicados pelo patrão, pelo trabalhador, ou "qualquer outro".

É interessante notar a entrada do Estado no âmbito das relações de trabalho, colocando-se como mediador da natureza conflitiva. Destaca-se, também, a importância que certas figuras-chave possuíam nessa relação, como o Delegado de Polícia e o escrivão, que eram o primeiro contato de um funcionário do Estado com a questão acidentária. Cabia ao escrivão relatar e ao Delegado confirmar o que e como havia ocorrido o acidente, as partes do inquérito policial e o encaminhamento ao Juiz de Direito.

Se existem semelhanças, no entanto, há diferenças fundamentais. Afinal, antes mesmo de ir para a esfera judicial (a Justiça Comum), o acidente passava pelo filtro de funcionários do Poder Executivo, mais propriamente da Chefia de Polícia, que era chefiada pelos Delegados de Polícia - que desde a Lei $\mathrm{n}^{\circ} 1.011$, de 16 de outubro de 1914, deveriam ser formados bacharéis em Direito. Estamos diante de uma figura-chave que possuía um peso importante no que tangia ao encaminhamento das questões de acidentes, uma vez que competia ao Delegado dar início ao inquérito que seria posteriormente desenrolado no Fórum. Muito provavelmente a nomeação de um cargo de Delegado de Polícia deveria ser muito disputada pela elite local, devido à importância social que representava e à remuneração paga pelo exercício da função. Eis mais uma vez a história política entrelaçando-se com a história social.

Apesar dessa permanência do monopólio da Justiça Comum sobre a referida legislação, ressalta-se que o advento da primeira Lei de Acidentes foi um marco jurídico importante, pois deslocou do Código Civil para o incipiente Direito do Trabalho a avaliação e o julgamento de algumas questões relativas ao mundo do trabalho (a questão acidentária, nesse caso).

Referida legislação ingressava na esfera das relações produtivas; consequentemente, novas estruturas jurídicas foram sendo criadas para acompanhar a necessidade de institucionalização das crescentes demandas trabalhistas em curso. O Decreto no 16.027, de 30 de abril de 1923 (BRASIL, 1923), criou o Conselho Nacional do Trabalho (CNT), este subordinado ao Ministério da Agricultura, Indústria e Comércio e composto por 12 membros dos quais oito eram representantes do governo, dois eram patrões e dois trabalhadores, todos escolhidos pelo presidente da República. Esse conselho teria a função de ser um órgão consultivo para assessorar o governo federal em matéria trabalhista. O que demonstra a clara hegemonia representada pelos interesses patronais e estatais sobre os trabalhadores. 
Porém, sem dúvida, foi com a criação do Ministério do Trabalho, Indústria e Comércio (MTIC), em 1930, quando foi instaurado o novo governo da chamada Revolução de 1930, que o Estado deu um passo significativo na formulação de políticas sociais mais incisivas para mediar os conflitos do mundo do trabalho, entre eles a questão acidentária. Cabia ao MTIC, por exemplo, a organização da relação das doenças consideradas profissionais, baseando-se, para isso, nas indicações da Organização Internacional do Trabalho (ALMEIDA, 2015). Ao menos do ponto de vista institucional, o Estado reconhecia a necessidade de intervir nas relações conflitivas entre capital e trabalho e formar uma estrutura que tentasse controlar a situação social que se agravava.

\section{A segunda Lei de Acidentes de trabalho (1934)}

A legislação de acidentes de trabalho, no Brasil, passou por profundas mudanças na década seguinte, após a revolução de 1930, visto que, em 10 julho de 1934, durante o governo provisório de Getúlio Vargas, foi promulgado o Decreto n 24.637 - a segunda Lei de Acidentes de Trabalho (BRASIL, 1934a). Esse decreto, além de manter a "teoria do risco profissional" ou do "fato do trabalho" como fundamento, obrigou, no seu art. 36, que os empregadores oferecessem a garantia de seguro contra acidentes de trabalho. Esse decreto exercia um maior controle do processo de seguro, uma vez que o empregador que não tivesse contrato com seguradora era obrigado a "[...] fazer um depósito nas repartições arrecadadoras federais, nas Caixas Econômicas da União ou no Banco do Brasil" (GOMES, 1979, p. 174).

Além disso, por meio do Decreto n 24.637 foi ampliado o conceito de doença profissional, porque, em seu art. 1, a lei estabelecia que enfermidades inerentes ou peculiares a certas atividades também estavam encampadas na denominação "doenças profissionais":

$\$ 1^{\circ}$ São doenças profissionais, para os efeitos da presente lei, além das inerentes ou peculiares a determinados ramos de atividade, as resultantes exclusivamente do exercício do trabalho, as resultantes exclusivamente especiais ou excepcionais em que o mesmo for realizado, não sendo assim consideradas as endêmicas quando por elas forem atingidos empregados habitantes da região. (BRASIL, 1934a).

Desse modo, pelo menos na letra da lei, começou a ser possível para os trabalhadores reivindicarem uma indenização pelas condições especiais ou excepcionais do trabalho, o que incluía um rol de doenças causadas pelo trabalho direto com substâncias como chumbo, fósforo, sílica, entre outras (ALMEDA, 2015). Do ponto de vista constitucional, a Carta de 1934, de 16 de julho (promulgada, portanto, apenas seis dias após o Decreto $\mathrm{n}^{\circ}$ 24.637), falava muito vagamente sobre a questão acidentária, somente afirmando, em seu art. 121, que:

$\$ 1^{\circ}$ - A legislação do trabalho observará os seguintes preceitos, além de outros que colimem melhorar as condições do trabalhador: h) assistência médica e sanitária ao trabalhador e à gestante, [...] e instituição de previdência, mediante contribuição igual da União, do empregador e do empregado, a favor da velhice, da invalidez, da maternidade e nos casos de acidentes de trabalho ou de morte. (BRASIL, 1934b, grifos nossos).

Apesar da instituição da Justiça do Trabalho no art. 122, destinada a "[...] dirimir questões entre empregadores e empregados” (BRASIL, 1934b), o monopólio da competência dos julgamentos relativos às questões acidentárias continuou sob a tutela da Justiça Comum dos Estados, tal como determinava o Decreto no 24.637/34.

Outro ponto importante na mudança da Lei foi a inserção de um cargo dentro da parte processual dos julgamentos, que foi a do Curador de Acidentes, por meio do art. 45, que determinava a sua função diante dos casos nos quais não fossem "[...] satisfeitas as obrigações legais por parte do responsável” (BRASIL, 1934a), leia-se quando o empregador não comunicava o fato do acidente à autoridade policial, tal como determinava a lei. 
Art. 45 A vítima ou seu representante, se não fôrem [sic] satisfeitas as obrigações legais por parte do responsável, poderá reclamar junto ao curador de Acidentes, ou correspondente órgão do Ministério Público, o qual, ouvido o mesmo responsável e parecendo-lhe procedente a reclamação, promoverá a abertura do inquérito policial, cujos autos serão, no prazo de quinze dias, enviados ao juízo competente. (BRASIL, 1934a).

O Curador de Acidentes era responsável não só por abrir o inquérito policial nos casos que não eram comunicados pelo empregador como também atuava como um conselheiro do Juiz da Comarca responsável por julgar o caso em questão. Como era um juizado da Vara da Fazenda Cível da Justiça Comum, era muito comum o mesmo Juiz atuar nos mais diversos casos e ser o responsável também pelos casos de acidente de trabalho. Cabe destaque que a lei atribui a discricionariedade ao curador de acidentes. Ela é aplicada quando "[...] parecendo-lhe procedente a reclamação" (art. 45) (BRASIL, 1934a). Com esse artigo, a brecha deixada para que muitas reclamações dos trabalhadores fossem julgadas "improcedentes" poderia ser grande, pois dependeria da correlação de forças entre trabalhadores, patrões e autoridades judiciais (curador de acidentes) para a sua aplicabilidade.

Assim como a figura do delegado de polícia continuou a ter um peso importante na materialização da lei, a inserção do curador de acidentes nos trâmites processuais configura mais uma intervenção do Estado nas relações produtivas, ao procurar contrabalançar o poder da autoridade policial. Deve-se salientar que ainda não existia a Justiça do Trabalho (criada pela Carta de 34, porém oficialmente apenas em 1941) ${ }^{3}$; por isso, a competência do julgamento das questões de acidente de trabalho e doenças profissionais ficava a cargo da Justiça Comum dos Estados.

\section{A "Reforma da Lei de Acidentes de Trabalho" de 1944}

Se durante a década de 1930 do século passado e começo da década de 1940 o Decreto $\mathrm{n}^{\circ} 24.637$ permaneceu como marco regulador dos casos de acidentes, durante a ditadura do Estado Novo (1937-1945), foi aprovada uma Reforma da Lei de Acidentes de Trabalho, implementada pelo Decreto-Lei no 7.036, de 1944.

O Estado Novo representou o autoritarismo de sua forma de governo com a intervenção no âmbito das relações entre capital e trabalho. Durante esse período, "[...] fomentar greves e abandonar o serviço nas indústrias da 'defesa nacional' eram atos de deserção, podendo acarretar de dois a seis anos de prisão" (NEGRO; SILVA, 2003, p. 52). Assim, vivia-se um período de aumento da produção econômica e da intensificação da exploração da força de trabalho, consequência do período da Segunda Guerra.

Por outro lado, procurava reparar de forma ampla os infortúnios ocasionados pelo aumento do ritmo de produção com a Reforma da Lei de Acidentes de Trabalho. Dentre os destaques importantes desse Decreto está a ampliação, em seu $1^{\circ}$ artigo, do conceito de infortúnio laboral, que equipara o acidente à doença resultante das condições de trabalho ${ }^{4}$; além disso, uma relação direta dessa ampliação do que engloba o acidente de trabalho está na admissão da teoria "concausa", que retirou do conceito de acidente de trabalho a causa única e exclusiva existente na legislação.

A legislação de acidentes de 1934 (Decreto ${ }^{\circ}$ 24.637) afirmava em seu art. $1^{\circ}, \$ 1$ que eram doenças profissionais as resultantes "[...] exclusivamente do exercício do trabalho" (BRASIL, 1934a); no Decreto-Lei ${ }^{\circ}{ }^{7.036}$, que trata da reforma da Lei de Acidentes de Trabalho, essa exclusividade anterior é retirada. Por sua vez, foram adotadas no art. $1^{\circ}$ da nova lei as palavras "direta ou indiretamente", resultantes das condições de trabalho.

Além dessa ampliação, também houve a distinção entre doenças profissionais inerentes a determinadas categorias profissionais, bem como de doenças resultantes das condições especiais ou excepcionais em que o trabalho é realizado e a introdução de um sistema de manutenção do salário para os casos de incapacidade permanente ou de morte do trabalhador.

Uma mudança substancial foi a modificação incorporada pelo Decreto de 1944 na transitoriedade 
das instituições de seguro particular para instituição de seguro estatal. Essa alteração fundamental da lei foi instituída pelo art. 112, o qual é reproduzido a seguir:

Art. 112. A partir de 1 de janeiro de 1949, as instituições de previdência social, então existentes, e que à data da vigência deste Decreto-lei ainda não possuíssem carteiras de acidentes do trabalho, providenciarão a criação de órgãos destinados ao seguro de acidentes do trabalho, aos quais passará, paulatinamente, o seguro das responsabilidades atribuídas aos empregadores, de forma que, a 31 de dezembro de 1953, cessem definitivamente as operações de seguros contra o risco de acidentes do trabalho, pelas sociedades de seguro e pelas cooperativas de seguro de sindicatos. (BRASIL, 1944).

A partir dessa disposição legal, as instituições particulares de seguro que haviam sido reguladas pelo Decreto no 24.637/34 acabaram perdendo espaço para a exclusividade do poder público em assumir os seguros de acidentes de trabalho por meio do Instituto de Aposentadorias e Pensões dos Empregados em Transportes e Cargas (IAPETEC), que foi criado pelo Decreto-Lei $\mathrm{n}^{\circ}$ 651, de 1938. Além dessa transição instituída pelo art. 112, o art. 111 da lei impedia que novas autorizações fossem dadas para as seguradoras atuarem no âmbito dos seguros de acidentes de trabalho. Transcrevemos o artigo devido à sua importância:

Art. 111. A partir da data da publicação desta lei não poderão ser concedidas autorizações a novas entidades seguradoras cabendo tão somente às instituições de previdência social, às sociedades de seguros e às cooperativas de seguros de sindicatos, que atualmente operam em seguro contra o risco de acidentes de trabalho, a cobertura dêsse [sic] risco, de acôrdo [sic] com as normas que forem fixadas em regulamento. (BRASIL, 1944).

Desse modo, a partir de 1945, pela lei Reforma de Acidentes de Trabalho - não poderiam ser autorizadas novas concessões para instituições particulares de seguro atuarem no âmbito dos acidentes de trabalho. Além disso, a lei determinava a data de 31 de dezembro de 1953 como limite para a atuação dessas companhias particulares, sendo a partir dessa data assumida a integralidade do Estado nas operações de seguro.

Em geral, sobre as Leis de Acidentes abordadas neste artigo, é possível perceber uma ampliação cada vez maior da interferência estatal nos conflitos entre capital e trabalho, de modo a dirimir as questões acidentárias e minimizar os efeitos negativos sobre a saúde dos trabalhadores no que tangia aos infortúnios laborais.

Se a primeira lei de 1919 atribuía o acidente como causa única no exercício do trabalho, "[...] exceto nos casos de força maior ou dolo da própria vítima” (BRASIL, 1919), a reforma da Lei de Acidentes de 1944 ampliou de forma significativa esse conceito, abrangendo aqueles acidentes produzidos "[...] direta ou indiretamente, lesão corporal, perturbação funcional, ou doença" (BRASIL, 1944), além do seu art. $3^{\circ}$, que considerava caracterizado o acidente "[...] ainda quando não seja êle [sic] a causa única e exclusiva da morte ou da perda ou redução da capacidade do empregado" (BRASIL, 1944).

Por outro lado, a competência para o julgamento das questões acidentárias continuou a cargo das Justiças Estaduais, nas suas respectivas comarcas, o que representava, do nosso ponto de vista, um modo de tentar manter um aparato de poder institucional regionalizado para solucionar essas questões entre representantes do Estado em escala local, pois envolvia, como já referido, diversas figuras-chave: o Delegado de Polícia, o Curador de Acidentes, o Escrivão, o trabalhador vítima e seus companheiros testemunhos, os representantes das empresas e das seguradoras de acidentes, os peritos médicos; enfim, todos os sujeitos inseridos em um mesmo contexto de uma mesma comunidade, bairro ou município. Nem mesmo a Constituição de 1946, quando se referia à Justiça do Trabalho e às suas funções no art. 123 mudou tal acepção:

Art. 123 - Compete à Justiça do Trabalho conciliar e julgar os dissídios individuais e coletivos 
entre empregados e empregadores, e, as demais controvérsias oriundas de relações, do trabalho regidas por legislação especial. $₫ 1^{\circ}-$ Os dissídios relativos a acidentes do trabalho são da competência da Justiça ordinária. (BRASIL, 1946, grifos nossos).

Desse modo, a nova legislação representou uma tentativa de remediar as doenças profissionais e os acidentes relacionados ao mundo do trabalho, $\mathrm{e}$ os inscreveu de forma normativa. Em nossa análise, concordamos com Mattos (2009, p. 213) de que é preciso relativizar a importância dessa legislação como um "ganho" para os trabalhadores. Não temos dúvida de que a legislação social trabalhista elaborada desde 1919 representou uma novidade em termos de proteção social, pois antes não existia praticamente legislação que regia o assunto ou era muito limitada. Essa afirmação, contudo, desconsidera as lutas sociais travadas por meio dos sindicatos e partidos políticos engajados na conquista de direitos e melhores salários.

\section{Considerações finais}

Nesse artigo, foi abordado o tema das fontes judiciais, em especial dos processos de acidentes de trabalho enquanto fontes históricas que possuem regras de constituição que lhes são próprias. Abordou-se o histórico da legislação de acidentes de trabalho no Brasil, no contexto da ampliação e do reconhecimento desses direitos no campo internacional. Também foi problematizada a questão do acesso às fontes judiciais como vestígios indiretos do passado, pois mesmo com os filtros dos poderes estatais, tais processos podem iluminar $\mathrm{o}$ campo de experiência dos trabalhadores na defesa de seus direitos relacionados à saúde, à dignidade de vida e de trabalho.

É fundamental, nesse sentido, ao se proceder a análise e a interpretação dos processos de acidentes de trabalho enquanto fontes, considerar esses elementos do ponto de vista da legislação acidentária no Brasil, mas também dessa legislação em permanente diálogo com o Direito do Trabalho e na sua interação recíproca entre a lei, a instituição judiciária, e a reivindicação política dos trabalhadores nas ruas e nos tribunais enquanto sujeitos ativos desse processo.

Não há como compreender onde se insere a luta por direitos e a relação com o poder Estatal se não levarmos em consideração a mobilização dos trabalhadores no interior dessas instituições, participando do jogo político como em uma partida de xadrez. É nesse sentido que a discussão sobre a conquista dos direitos sociais no Brasil, dentre eles da legislação de acidentes de trabalho, deve caminhar lado a lado com o debate sobre a experiência dos trabalhadores não só nos sindicatos mas também no interior das instituições jurídicas e estatais pela ampliação desses direitos.

\section{Notas}

1 Sobre as críticas do marxismo e do estruturalismo à história política, ver: Borges, 1991/1992; Félix, 1999.

2 "A história política é psicológica e ignora condicionamentos; é elitista, biográfica mesmo, e ignora a sociedade global e as massas que a compõem; é qualitativa e ignora o serial; visa ao particular e ignora a comparação; é narrativa e ignora a análise; é materialista e ignora o material; é ideológica e não tem disso consciência; é parcial e não sabe que o é; atém-se ao consciente e ignora o inconsciente; é pontual e ignora o longo prazo; em uma palavra, porque essa palavra resume tudo na gíria dos historiadores, é factual” (JULLIARD, 1988, p. 181).

3 A Justiça do Trabalho, como ficou conhecida, foi oficialmente criada em maio de 1941, no dia destinado aos trabalhadores, durante a ditadura do Estado Novo varguista. Essa instituição, que fora criada para resolver os conflitos inseridos no mundo do trabalho, entre patrões e trabalhadores, já vinha se desenhando décadas antes, entre debates parlamentares, reivindicações trabalhistas e escritos de juristas voltados para a causa operária.

4 "Art. $1^{\circ}$ Considera-se acidente do trabalho, para os fins da presente lei, todo aquêle [sic] que se verifique pelo exercício do trabalho, provocando, direta ou indiretamente, lesão corporal, perturbação funcional, ou doença, que determine a morte, a perda total ou parcial, permanente ou temporária, da capacidade para o trabalho" (BRASIL, 1944).

\section{Referências}

ALMEIDA, Anna Beatriz de Sá. As doenças 'do trabalho' no Brasil no contexto das políticas públicas voltadas ao trabalhador (1920-1950). 
Revista Mundos do Trabalho, v. 7, n. 13, p. 65-84, jan./jun. 2015.

ANSART, Pierre. Les Cliniciens des passions politiques. Paris: Senil, 1997.

ARAVANIS, Evangelia. Um olhar sobre os Processos de Acidentes de Trabalho no Rio Grande do Sul (1934-1950). Revista Aedos, Porto Alegre, n. 8, v. 2, p. 31, 2009.

BORGES, Vavy Pacheco. História e Política: laços permanentes. Revista Brasileira de História, São Paulo, v. 12, n. 23/24, set. 1991/ago. 1992.

BRASIL. Decreto no 3.724, de 15 de janeiro de 1919. Regula as obrigações resultantes dos acidentes no trabalho. Disponível em: http://www2. camara.leg.br/legin/fed/decret/1910-1919/decreto3724-15-janeiro-1919-571001-publicacaooriginal94096-pl.html. Acesso em: 20 jun. 2018.

BRASIL. Decreto $n^{\circ}$ 16.027, de 30 de abril de 1923. Cria o Conselho Nacional do Trabalho. Disponível em: <http://www2.camara.leg.br/legin/ fed/decret/1920-1929/decreto-16027-30-abril1923-566906-publicacaooriginal-90409-pe.html>. Acesso em: 20 jun. 2018.

BRASIL. Decreto $n^{\circ}$ 24.637, de 10 de julho de 1934a. Estabelece sob novos moldes as obrigações resultantes dos acidentes do trabalho e dá outras providências. Disponível em: http://www2.camara. leg.br/legin/fed/decret/1930-1939/decreto-2463710-julho-1934-505781-publicacaooriginal-1-pe. html. Acesso em: 20 jun. 2018.

BRASIL. Constituição Federal (1934). Constituição da República dos Estados Unidos do Brasil, de 16 de julho de 1934b. Disponível em: http:// www.planalto.gov.br/ccivil_03/constituicao/ constituicao34.htm. Acesso em: 25 jun. 2018.

BRASIL. Decreto-Lei no 7.036, de 10 de novembro de 1944. Reforma da Lei de Acidentes do Trabalho. Disponível em: http://www2.camara.leg.br/ legin/fed/declei/1940-1949/decreto-lei-7036-10- novembro-1944-389493-publicacaooriginal-1-pe. html. Acesso em: 23 jun. 2018.

BRASIL. Constituição Federal (1946). Constituição da República dos Estados Unidos do Brasil, de 18 de setembro de 1946. Disponível em: http:// www.planalto.gov.br/ccivil_03/constituicao/ constituicao46.htm. Acesso em: 25 jun. 2018.

BURKE, Peter. Abertura à nova história, seu passado e seu futuro. In: BURKE, Peter (Org.). A Escrita da história: novas perspectivas. São Paulo: Editora da Universidade Estadual Paulista, 1992. p. 7-38.

CHALHOUB, Sidney. O conhecimento da História, o Direito à Memória e os Arquivos Judiciais. In: Curso de Formações de Multiplicadores em “Políticas de resgate, preservação, conservação e restauração do patrimônio histórico da Justiça do Trabalho no Rio Grande do Sul”. Porto Alegre, 2005. Disponível em: http://iframe.trt4.jus.br/ portaltrt/htm/memorial/index.htm. Acesso em: 23 jun. 2018.

CHALHOUB, Sidney; SILVA, Fernando Teixeira da. Sujeitos no imaginário acadêmico: escravos e trabalhadores na historiografia brasileira desde os anos 1980. Cadernos do AEL, v. 14, n. 26, p. 12-47, 2009.

FALCON, Francisco. História e poder. In: CARDOSO, Ciro Flamarion; VAINFAS, Ronaldo (Org.). Domínios da história: ensaios de teoria e metodologia. Rio de Janeiro: Campus, 1997. p. 6189.

FARGE, Arlette. O sabor do arquivo. Tradução de Fátima Murad. São Paulo: Edusp, 2009.

FÉLIX, Loiva Otero. Historiografia política: impasses e rumos nas décadas de 1970-90. Logos, Canoas, v. 11, n. 1, p. 5-11, maio 1999.

FERRAZ, Eduardo Luís Leite. Acidentados e Remediados: a lei de acidentes no trabalho na Piracicaba da Primeira República (1919-1930). Revista Mundos do Trabalho, v. 2, n. 3, p. 206-235, jan./jun. 2010 
FRENCH, John. Afogados em leis: a CLT e a cultura política dos trabalhadores brasileiros. São Paulo: Fundação Perseu Abramo, 2001.

GALLO, Óscar. Acidentes de trabalho na Colômbia. Doutrina, lei e jurisprudência (1915-1950). Revista Mundos do Trabalho, v. 7, n. 13, p. 129-149, jan./ jun. 2015.

GINZBURG, Carlo. Mitos, Emblemas, Sinais: Morfologia e História. São Paulo: Companhia das Letras, 1989.

GINZBURG, Carlo. O Queijo e os Vermes. São Paulo: Companhia de Bolso, 2013.

GOMES, Ângela Maria de Castro. Burguesia e trabalho: política e legislação social no Brasil 19171937. Rio de Janeiro: Editora Campus, 1979.

GOMES, Ângela Maria de Castro; SILVA, Fernando Teixeira. A Justiça do Trabalho e sua História: os direitos dos trabalhadores no Brasil. Campinas: Editora Unicamp, 2012.

GRINBERG, Keila. A História nos porões dos arquivos judiciários. In: PINSKY, Carla Bassanezi; LUCA, Tânia Regina de (Org.). O historiador e suas fontes. São Paulo: Contexto, 2009.

JULLIARD, Jacques. A Política. In: LE GOFF, Jacques; NORA, Pierre (Org.). História: novas abordagens. 3. ed. Rio de Janeiro: Francisco Alves, 1988. p. 180-195.

MANDELLI, Bruno. As fontes judiciais como material de pesquisa para história: os processos de acidentes de trabalho e as doenças profissionais. In: CONGRESSO IBERO-AMERICANO DE HUMANIDADES, CIÊNCIAS E EDUCAÇÃO, 3..
22-25 maio 2018, Criciúma. Anais eletrônicos... Criciúma: UNESC, 2018. Disponível em: http:// periodicos.unesc.net/congressoeducacao/article/ download/4525/4137. Acesso em: 20 jun. 2018.

MATTOS, Marcelo Badaró. Trabalhadores e Sindicatos no Brasil. São Paulo: Expressão Popular, 2009.

MOTTA, Rodrigo Patto Sá. Culturas políticas na história: novos estudos. Belo Horizonte: Argumentum, 2009.

NEGRO, Antonio Luigi; SILVA, Fernando Teixeira da. Trabalhadores, sindicatos e política (19451964). In: FERREIRA, Delgado (Org.). O Brasil Republicano: o tempo da experiência democrática - da democratização de 1945 ao golpe civil-militar de 1964. Rio de Janeiro: Civilização Brasileira, 2003. p. 49-96.

RÉMOND, René (Org.). Por uma história política. Rio de Janeiro: Ed. da FGV, 2003.

SIRINELLI, Jean-François. Para uma História Cultural. Lisboa: Editorial Estampa, 1998.

SCHMIDT, Benito B.; SPERANZA, Clarice G. Processos trabalhistas: de papel velho a patrimônio histórico.In: PAULA, ZueleideC. de; ROMANELLO, Jorge L.; MENDONÇA, Lúcia G. (Orgs.). Polifonias do Patrimônio. Londrina: Eduel, 2012, p. 214-230.

SOUZA, Samuel Fernando de. "Coagidos ou Subornados": trabalhadores, sindicatos, Estado e as leis do trabalho nos anos 1930. 2006. $225 \mathrm{f}$. Tese (Doutorado em História) - Programa de PósGraduação em História, Universidade Estadual de Campinas, Campinas, 2006. 